\title{
Plasma homocysteine is elevated in COPD patients and is related to COPD severity
}

\author{
Terence AR Seemungal ${ }^{1}$ \\ Johanna Cho Fook Lun ${ }^{1}$ \\ Gershwin Davis ${ }^{2}$ \\ Carlos Neblett ${ }^{1}$ \\ Nkhabe Chinyepi ${ }^{1}$ \\ Christina Dookhan ${ }^{1}$ \\ Samantha Drakes ${ }^{1}$ \\ Elizabeth Mandeville ${ }^{1}$ \\ Fatima $\mathrm{Nana}^{1}$ \\ Seatshogeng Setlhake ${ }^{1}$ \\ Celia Poon King ${ }^{2}$ \\ Lexley PintoPereira ${ }^{2}$ \\ Jerome Delisle ${ }^{3}$ \\ Thomas MA Wilkinson ${ }^{4}$ \\ Jagwiga A Wedzicha ${ }^{4}$ \\ ${ }^{1}$ Departments of Clinical Medical \\ Sciences; ${ }^{2}$ Paraclinical Sciences; \\ ${ }^{3}$ Centre for Medical Sciences \\ Education; ${ }^{4}$ Faculty of Medical \\ Sciences University of the West \\ Indies, St Augustine Campus, Trinidad \\ and Tobago; Academic Unit of \\ Respiratory Medicine, University \\ College Medical School, University \\ College London, England
}

Correspondence:Terence Seemungal Senior Lecturer, Department of Clinical Medical Sciences, Faculty of Medical Sciences University of the West Indies, St Augustine Campus, Trinidad and Tobago Tel +86866343332

Fax +86866343332

Email tseemungal@aol.com
Background: Although recent studies have found that total plasma homocysteine (tHCY) and chronic obstructive pulmonary disease (COPD) are both risk factors for cardiac disease, there have been few studies of plasma homocysteine levels in COPD patients. We tested the hypothesis that total plasma homocysteine (tHCY) would be elevated in patients diagnosed with COPD compared with controls.

Methods: We studied 29 COPD outpatients and 25 asymptomatic subjects (controls) over age 55 years with measurement of forced expiratory volume in one second $\left(\mathrm{FEV}_{1}\right)$, forced vital capacity (FVC), St. Georges Respiratory Questionnaire (SGRQ) score, tHCY and serum C-reactive protein (sCRP).

Results: There was no difference between controls vs. COPD patients in mean age or gender but mean (SD) FEV 1 was 2.25 (0.77) vs 1.43 (0.60) L; FEV \% predicted 76.1 (17.2) vs 49.1 (16.3) $\mathrm{p}<0.001$ in both cases. Median (IQR) tHCY was $8.22(6.63,9.55)$ in controls vs 10.96 $(7.56,13.60) \mathrm{micromol} / \mathrm{l}$ for COPD, $\mathrm{p}=0.006$ and $\mathrm{sCRP} 0.89(0.47,2.55)$ vs $2.05(0.86,6.19)$ $\mathrm{mg} / \mathrm{l}, \mathrm{p}=0.023$. tHCY $(\log )$ was also higher in $(\mathrm{r}, \mathrm{p})$ smokers $(0.448,0.001)$, patients with low FEV $_{1} \%(-0.397,0.003)$, males $(0.475,<0.001)$, but high SGRQ Total score $(0.289,0.034)$, and high sCRP $(0.316,0.038)$. $\mathrm{tHCY}(\log )$ was independently related to (regression coefficient, p) $\operatorname{sCRP}(\log )(0.087,0.024)$, male gender $(0.345,<0.001)$ and presence of COPD $(0.194$, 0.031). Median (IQR) tHCY GOLD Stage I and II 8.05 (7.28, 11.04), GOLD Stage III and IV: 11.83(9.30, 18.30); $\mathrm{p}=0.023$.

Conclusions: Plasma homocysteine is significantly elevated in COPD patients relative to age and sex-matched controls and is related to serum CRP and COPD severity.

Keywords: COPD, Homocysteine, CRP, SGRQ, FEV 1

\section{Introduction}

There has been an increase in the prevalence of and mortality from chronic obstructive pulmonary disease (COPD) worldwide. The World Health Organization has predicted that by 2020, COPD will rise from its current ranking as the 12th most prevalent disease worldwide to the 5th and from the 6th most common cause of death to the 3rd (Barnes 2000). Amongst the reasons for the dramatic increase in COPD prevalence include reduced mortality from other causes such as cardiovascular diseases in industrialized countries and infectious diseases in developing countries, along with a marked increase in cigarette smoking and environmental pollution in developing countries (Barnes 2000).

Chronic obstructive pulmonary disease is characterized by airflow limitation that is not fully reversible, progressive, associated with an abnormal inflammatory response of the lungs to noxious particles or gases (Buist 2006) and the presence of low grade systemic inflammation (Wedzicha 2000; Sin 2003). Amongst the systemic inflammatory markers serum C-reactive protein (sCRP) has emerged as a major systemic indicator of vascular risk (Danesh 1998; Sin 2003). However recent studies have demonstrated that plasma 
homocysteine may be considered to be a strong marker of cardiovascular risk (Homocysteine Studies 2002; Bodi 2005).

Most studies which have looked at systemic mechanisms and vascular risk in COPD have been undertaken in developed world subjects (Barnes 2000; Wedzicha 2000; Sin 2003) but in the West Indies there are lifestyle differences compared with the developed world and risk factors for morbidity and mortality may differ. Epidemiological studies of diseases in Trinidad and Tobago have concentrated on cardiovascular and metabolic diseases without much reference to respiratory diseases apart from asthma (Miller 1989; Scott 1998; PintoPereira 2002; Cockburn 2005), however a recent study of COPD in Trinidad has reported that patients with a history of vascular disease (VD) are more likely to have a low forced expiratory volume in one second $\left(\mathrm{FEV}_{1}\right)$ (Harrinarine 2005). We postulated that blood markers of cardiac risk (tHCY and SCRP) would be elevated in COPD patients and that there would be an inverse relation between these markers of cardiac risk and spirometric indices of airway obstruction.

\section{Methods}

\section{Selection of COPD patient and controls}

Patients were recruited in 2005 from the Chest Clinic at Eric Williams Medical Sciences Complex (EWMSC), Faculty of Medical Sciences, St. Augustine, Trinidad and Tobago and all were outpatients who were know to have COPD. Asymptomatic subjects (controls) for this study were recruited during the study period in response to advertisement. The recruitment record included demographic variables, smoking, medical history and diet (Refsum 2004).

Ethical permission was obtained from the Institutional Review Board of the University of the West Indies prior to recruitment. Subjects were informed of the study and gave written consent prior to participating in the study.

\section{Inclusion criteria for COPD patients}

A prior diagnosis of COPD stated in the patients' medical notes and postbronchodilator $\mathrm{FEV}_{1}$ /forced vital capacity (FVC) ratio of less than $70 \%$ (Buist 2006). All COPD patients were over the age of fifty-five years.

\section{Inclusion criteria for controls}

Asymptomatic controls were defined as persons over the age of fifty-five years without any known medical illness and who were symptom free.

\section{Exclusion criteria for COPD patients}

Patients were excluded with any of the following (AARC 1996; Wedzicha 2000; Refsum 2004): hemoptysis of unknown origin; pneumothorax; unstable cardiovascular status, recent myocardial infarction or pulmonary embolus thoracic; abdominal or cerebral aneurysms; recent eye surgery eg, cataract; presence of an acute disease process that might interfere with test performance; recent surgery of thorax or abdomen; acute infection, inflammatory diseases such as rheumatoid arthritis, or history of kidney disease.

\section{Exclusion criteria for controls}

The exclusion criteria for the controls were the presence of any known disease or presence of any acute or chronic symptoms.

\section{Measurement of spirometric variables}

A handheld turbine spirometer (MicroSpirometer Cat No: MS01 Micromedical Limited P.O Box 6 Rochester, Kent, ME1 2AZ, UK) was used to measure postbronchodilator $\mathrm{FEV}_{1}$ and FVC. The spirometer met the requirements of the American Thoracic Society (ATS) (ATS 1994) and was calibrated appropriately (AARC 1996) and did not require recalibration (Seemungal 2000). Post-bronchodilator spirometric indices were measured 20 minutes after the subject inhaled two puffs of salbutamol -100 $\mu \mathrm{g}$ (AARC 1996). COPD severity (Crapo 1981) was classified according to the Global Initiative for Obstructive Lung Disease (GOLD) (Buist 2006).

\section{Sample collection and analysis}

Nonfasting venous blood samples were obtained from subjects for serum CRP analysis and plasma samples with ethylene diamine tetra acetic acid (EDTA) as anticoagulant used for tHCY analysis. The latter were immediately placed on ice in an icebox after collection and centrifuged within two hours, samples were stored at $-20^{\circ} \mathrm{C}$ until analysis within one month. The Abbott AxSym Homocysteine assay was utilized to quantitatively measure tHCY levels. It was based on the Fluorescence Polarization Immunoassay (FPIA) technology. This assay had a within day and day to day imprecision of $(\mathrm{CV}<5 \%)$ and a recovery of $99.6 \%$. Intraassay imprecision $1.1-1.8 \%$, interassay $2.4 \%-6.7 \%$. with an analytical sensitivity of $0.7 \mu \mathrm{mol} / \mathrm{L}$. Serum CRP concentrations were measured using the Tina-Quant sCRP (Latex) high sensitive immunoturbidimetric assay on the Roche/Hitachi 912 Automatic Analyzer (Roche Diagnostics, GmbH, D-68298 Mannheim). The measuring range was 0.1-20 $\mathrm{mg} / \mathrm{L}$ with a detection limit of $0.03 \mathrm{mg} / \mathrm{L}$.

\section{Health related quality of life and dietary vitamin intake \\ Health related quality of life}

The health related quality of life (HRQOL) was determined using the St. George's respiratory questionnaire (SGRQ) 
(Jones 1991). The SGRQ is a disease specific instrument that contains 50 items in 3 subscales (Symptoms, Activity, and Impact) (Jones 1991). The 3 components are transformed into a score from 0 to 100 (Jones 1991). The total score was calculated from responses to all 50 items (Jones 1991). Higher scores indicate poorer health status. The SGRQ was modified for use in Trinidad and was reviewed by four authors (TARS, GD, LPP, JD) using the MAPI Research Institute Method (Davison 2004). The only change made to the questionnaire was replacing the culturally (for the West Indies) irrelevant item "shovelling snow" by "dig in garden" in Section 6 . This change did not affect the sense of the questionnaire and thus the weighting of the various parts of the questionnaire remained unchanged (Broekhuizen 2005).

\section{Dietary vitamin intake}

The food frequency questionnaire (FFQ) (Nutrition Assessment Shared Resource, 1100 Fairview Ave. N. M1-B208 Seattle, WA 98109-1024) was used to assess Vitamin B6, B12, and folate status in individuals according to the United States dietary allowance (USDA) National Nutrient Database for Standard Reference (National Agricultural Library 2004) since deficiencies in folate, Vitamins B6 and B12 can lead to hyperhomocysteinaemia (Refsum 2004). The FFQ was used to estimate habitual food intake of individuals and it consisted of a list of food items and a set of frequency-of-use response categories eg, per day, per week, per month or per year. Open-ended questions were avoided. Data gathered with the FFQ was ranked in classes of small, medium and large intakes (National Agricultural Library 2004) and the total intake scored (Fabiosa 1997). To evaluate the nutritional outcomes, the nutrient intake levels were compared with their respective United States recommended dietary allowances (RDAs) to determine the degree of shortfall (or excess) from the RDAs. In order to be comparable to the RDA standard, the nutrient intake was expressed on a per day basis (Fabiosa 1997).

\section{Statistical analysis}

Since there was no previously published West Indian data on homocysteine levels in the age groups studied the sample size was estimated using data from a previous study of inflammatory markers in COPD (Wedzicha 2000). In the latter study, the mean plasma fibrinogen in COPD patients was $33 \%$ higher when compared to normal age-matched subjects. In our study, we assumed a more conservative difference of $16.5 \%$ for the means of tHCY between normal and COPD subjects while allowing for the similar differences in variability observed in plasma fibrinogen. In order to detect a rise of $16.5 \%$ in mean tHCY between normal and COPD subjects, with a statistical power of $90 \%$ at the $5 \%$ significance level, we calculated a sample size of 23 subjects in each group.

For analysis, patients were classified as either smokers if they ever smoked or as nonsmokers. Categorical data were expressed in number (percentage). Parametric continuous variables were expressed as mean (SD) (standard deviation) while non-parametric continuous variables were expressed as median (interquartile range). sCRP were both normalized by logarithmic transformation and so Pearson's correlation was used to determine binary relationships with these two variables. Differences between continuous variables were determined by t-test or Mann Whitney U-test as appropriate. Categorical variables were compared by the chi-square test. Backward linear regression, with $\mathrm{tHCY}(\log )$ as outcome variable, was used to determine independent effects of variables that showed significant univariate relationship with tHCY $(\log )$.

\section{Results \\ Demographics and spirometry}

Table 1 shows that a total of 54 subjects (ethnicity: African 18, East Indian 25, Chinese 2, Mixed ancestry 9) were recruited of which 25 were controls and 29 were COPD patients. Among all subjects, older patients were more likely to have a lower $\mathrm{FEV}_{1}$ (rho $=-0.557, \mathrm{p}=0.002$ ) and FVC $(-0.487,0.007)$. Also there was no significant difference between Africans and East Indians in age, gender, body mass index, $\mathrm{FEV}_{1} \%$ predicted or $\mathrm{FEV}_{1} / \mathrm{FVC}_{0}(\mathrm{p}>0.05$ in all cases).

COPD patients had a lower body mass index (BMI) than asymptomatic controls but age, height, ethnicity and gender distribution were similar (Table 1). In the asymptomatic controls, 22 never smoked, 2 quit greater than one year prior to the study and one quit within the past twelve months. In the COPD group, 5 never smoked, 13 quit greater than 1 year ago, 3 quit within the past year and 8 currently smoked. Co-morbidities amongst the 29 COPD patients were as follows: 12 in all with either cardiac disease $(\mathrm{N}=9)$ and/or diabetes mellitus $(\mathrm{N}=6)$. The distribution of COPD severity amongst COPD patients was: GOLD stages 1 and $2(\mathrm{~N}=15)$, GOLD stages 3 and $4(\mathrm{~N}=14)$.

\section{Quality of life}

As expected, Table 1 shows that the SGRQ total and component scores were uniformly higher in COPD patients com- 
Table I Demographical data, lung function, SGRQ scores, tHCY and sCRP among controls and COPD patients. Data is shown either as mean (SD) or median (25th centile, 75 th centile)

\begin{tabular}{|c|c|c|c|}
\hline Characteristics & Controls $(\mathbf{N}=\mathbf{2 5})$ & COPD (N = 29) & p-value \\
\hline Age/yrs mean (SD) & $64.8(6.8)$ & $69.1(9.8)$ & 0.137 \\
\hline Height/cms & $164.3(9.3)$ & $164.8(9.2)$ & 0.849 \\
\hline Gender: Male N (\%) & $16(64)$ & $23(79)$ & 0.218 \\
\hline Ethnicity $\mathrm{N}(\%)^{*}$ & & & 0.061 \\
\hline East Indians (Indo-Trinidadian) & $9(36)$ & $16(55)$ & \\
\hline African (Afro-Trinidadian) & $8(32)$ & $10(35)$ & \\
\hline Other & $8(32)$ & $3(10)$ & \\
\hline BMI kg/m² (median (IQR) & $27.4(25.9,29.9)$ & $24.0(20.5,27.0)$ & 0.001 \\
\hline \multicolumn{4}{|l|}{ Lung Function (mean (SD)) } \\
\hline $\mathrm{FEV}, / \mathrm{L}$ & $2.25(0.77)$ & $\mathrm{I} .43(0.60)$ & $<0.001$ \\
\hline $\mathrm{FVC} / \mathrm{L}$ & $2.91(1.02)$ & $2.72(0.82)$ & 0.18 \\
\hline $\mathrm{FEV}_{1} / \mathrm{FVC} \%$ & $78.1(8.3)$ & $53.1(14.0)$ & $<0.001$ \\
\hline $\mathrm{FEV}, \%$ predicted & $76.1(17.2)$ & $49.1(16.3)$ & $<0.00 \mathrm{I}$ \\
\hline \multicolumn{4}{|l|}{ SGRQ Scores (median (IQR)) } \\
\hline Impact & $0.0(0.0,0.0)$ & $35.7(10.0,50.8)$ & $<0.001$ \\
\hline Activity & $6.2(0.0,12.2)$ & $47.7(26.0,66.3)$ & $<0.001$ \\
\hline Symptoms & $0.0(0.0,8.1)$ & $49.3(19.1,64.0)$ & $<0.001$ \\
\hline Total & $2.8(0.0,9.3)$ & $44.2(18.4,55.0)$ & $<0.001$ \\
\hline tHCY/micromol/L & $8.22(6.63,9.55)$ & $10.96(7.56,13.60)$ & 0.006 \\
\hline $\mathbf{s C R P} / \mathrm{mg} / \mathrm{L}$ & $0.890(0.47,2.55)$ & $2.050(0.86,6.19)$ & 0.023 \\
\hline
\end{tabular}

Abbreviations: SD, standard deviation; FEV , forced expiratory volume in I second; FVC, forced vital capacity; SGRQ, St. George's Respiratory Questionnaire; tHCY, total plasma homocysteine; sCRP, serum C-reactive protein; BMI, Body Mass Index.

Note: *Ethnicity was determined from the patient's own perception.

pared with controls. The SGRQ total and component scores were strongly correlated with each other with correlations ranging from 0.622 to 0.933 ( $\mathrm{p}<0.001$ in all cases). Table 2 shows that the SGRQ total and component scores were higher in COPD patients and those with low $\mathrm{FEV}_{1}, \mathrm{FEV}_{1} \%$ and $\mathrm{FEV}_{1} / \mathrm{FVC}$ ( $\mathrm{p}<0.001$ in all cases). The SGRQ scores were all higher in the smokers.

\section{Total plasma homocysteine and serum C-reactive protein}

Table 1 shows that median tHCY and median sCRP were higher in the COPD patients. Since this is the first study of homocysteine in this population we also state the means for comparison: mean (SD) tHCY in asymptomatic controls was $8.18(1.82) \mu \mathrm{mol} / \mathrm{L}$ and in COPD patients 11.96 (5.87) $\mu \mathrm{mol} / \mathrm{L}$; mean (SD) sCRP was $1.83 \mathrm{mg} / \mathrm{L}$ in the asymptomatic controls and $4.35 \mathrm{mg} / \mathrm{L}$ in the COPD group. COPD patients with cardiac disease or diabetes mellitus were unlikely to have a higher plasma homocysteine or serum CRP level than other COPD patients ( $p>0.120$ in all cases). There was no significant relationship between ethnicity and tHCy or sCRP. Further, tHCY was not related to B12, folic acid or B6 intake as estimated by the food frequency questionnaire ( $p>0.200$ in all cases). $25 \%$ of patients consumed alcohol, but this was unrelated to tHCY levels, rho $=0.070, \mathrm{p}=0.668$.
Table 3 shows that higher levels of tHCY and sCRP were found in COPD patients, smokers and Table 2 shows that higher levels of tHCY and sCRP were also related to higher SGRQ symptoms, impacts, and total scores. In addition, tHCY was likely to be higher in males and to low $\mathrm{FEV}_{1} \%$ predicted or low $\mathrm{FEV}_{1} / \mathrm{FVC}$. $\mathrm{tHCY}(\log )$ and $\mathrm{sCRP}(\log )$ were significantly correlated over all subjects as illustrated in Figure 1.

Figure 2 shows that COPD patients with high stage disease (GOLD stages 3 and 4 ) were more likely to have a high tHCY (rho $=0.429, \mathrm{p}<0.020$ ) than those with low stage disease (GOLD stages 1 and 2). There was a nonsignificant

Table 2 Correlations (Spearmans) between variables in Table I and SGRQ symptoms, impacts, activities and total scores, ( $\mathrm{N}=54$ subjects). (NS = Not statistically significant)

\begin{tabular}{|c|c|c|c|c|}
\hline Variable & Symptoms & Impacts & Activities & Total score \\
\hline $\mathrm{FEV}_{1}^{* * * *}$ & -0.498 & $-0.46 I$ & -0.516 & -0.595 \\
\hline $\mathrm{FEV}, \% * * *$ & -0.584 & -0.577 & -0.620 & -0.644 \\
\hline $\mathrm{FEV}_{1} / \mathrm{FVC} * * *$ & -0.576 & $-0.64 I$ & -0.437 & -0.558 \\
\hline BMI* & -0.278 & -0.338 & NS & NS \\
\hline Smoker* & 0.555 & 0.649 & 0.448 & 0.582 \\
\hline thCY* & 0.295 & 0.330 & NS & 0.289 \\
\hline sCRP* & 0.339 & 0.286 & NS & 0.316 \\
\hline
\end{tabular}

Note: ${ }^{* * *} \mathrm{p}<0.00$ I for all correlations in this row; ${ }^{*} \mathrm{p}<0.05$ for all correlations in this row. Except where NS is stated. 
Table 3 Correlations (Pearsons) between tHCY(log), sCRP(log) and the baseline variables. (Statistically significant relationships are in bold type, $\mathrm{P}<0.05, \mathrm{~N}=54$ subjects.)

\begin{tabular}{|c|c|c|c|c|}
\hline & \multicolumn{2}{|c|}{ tHCY(log) } & \multicolumn{2}{|c|}{ sCRP(log) } \\
\hline & rho & $\mathbf{p}$ & rho & $\mathbf{p}$ \\
\hline COPD & 0.418 & 0.002 & 0.327 & 0.016 \\
\hline Male Gender & 0.475 & $<0.001$ & 0.059 & 0.672 \\
\hline Age & 0.223 & 0.105 & 0.173 & 0.212 \\
\hline BMI & -0.120 & 0.387 & -0.091 & 0.514 \\
\hline Ethnicity & -0.191 & 0.169 & -0.193 & 0.161 \\
\hline Smoker & 0.448 & 0.001 & 0.410 & 0.002 \\
\hline $\mathrm{FEV}_{\text {, }}$ & -0.168 & 0.226 & -0.263 & 0.055 \\
\hline FVC & 0.000 & - & -0.211 & 0.126 \\
\hline $\mathrm{FEV}_{1} / \mathrm{FVC}$ & -0.298 & 0.028 & -0.225 & 0.102 \\
\hline FEV ${ }_{1} \%$ Predicted & -0.397 & 0.003 & -0.272 & 0.047 \\
\hline $\mathrm{tHCY}$ & - & - & 0.377 & 0.005 \\
\hline
\end{tabular}

trend toward a higher median SCRP in patients with high vs. low stage COPD (3.48 vs. $1.64 \mathrm{mg} / \mathrm{L}, \mathrm{p}=0.565$ ). However tHCY and sCRP were significantly related in the COPD patients $(\mathrm{N}=29)$, rho $=0.415, \mathrm{p}=0.025$.

\section{Multivariate analysis of factors affecting plasma homocysteine levels}

Backward multiple regression for all subjects $(\mathrm{N}=54)$ with plasma homocysteine $(\log )$ as outcome variable revealed independent relationships with serum CRP $(\log )$, presence of COPD and male gender but not SGRQ Total score (dichotomized about the median) or smoking history (Table 4). If the regression was repeated with $\mathrm{FEV}_{1} \%$ instead of presence of $\mathrm{COPD}$ as the lung function variable results were similar, with an inverse relationship between $\mathrm{FEV}_{1} \%$ and $\mathrm{tHCY}(\log )$.

When the regression analysis was repeated amongst COPD patients only $(\mathrm{N}=29)$, tHCY $(\log )$ was independently related to high $\mathrm{sCRP}(\log )(\mathrm{B}=0.123, \mathrm{p}=0.046)$ and high stage COPD [GOLD 3 and 4] $(B=0.326, p=0.023)$ and, again, effects of quality of life and smoking could not be independently distinguished.

\section{Discussion}

This is the first study to our knowledge that shows the relationship between plasma tHCY and spirometric measurements in a West Indian population, the study extends and supports the findings of two previous studies (Anderson 2001; Kai 2005). We found a negative correlation between $\mathrm{FEV}_{1}$ and tHCY in the subjects studied and, consistent with other centres, a high sCRP in COPD patients (Broekhuisen 2005; Dahl 2007). tHCY and sCRP were related to COPD severity using the GOLD guidelines classification and this relationship was supported by relationships with poor quality of life scores in the bivariate analyses. Total plasma homocysteine was greater in men, subjects with low $\mathrm{FEV}_{1} / \mathrm{FVC}$ ratio and low $\mathrm{FEV}_{1} \%$ predicted. Our study revealed a positive correlation between tHCY and sCRP in both patients and controls.

This is the first study to measure health-related quality of life in a West Indian COPD population using the SGRQ and the first to show a relationship with plasma homocysteine. Several instruments have been advocated for measurement of quality of life; however as with most questionnaires of this type, they may be rather insensitive to changes in health (Jones 1991). The SGRQ has the advantage of allowing direct comparison between different patient populations and treatment groups and has been shown to be responsive when used for these comparisons (Jones 1991; Seemungal 1998). The Total SGRQ score in our group of COPD patients was 44.2 as compared with 56.7 in the East London cohort of moderate to severe COPD patients (Seemungal 1998), like the East London Study, all of our COPD patients were outpatients. In this study we presented the data for SGRQ in the controls as this is the first study of its kind in the West Indies. As in other studies we have found a relationship between impaired quality of life, severity of airflow obstruction and elevation of the serum inflammatory marker C-reactive protein (Broekhuisen 2005).

tHCY was unrelated to dietary vitamin (B12, folate and B6) intake however, median tHCY in COPD patients was higher when compared with controls, and in smokers compared with nonsmokers. In the multivariate analysis the effects of COPD outweighed those of smoking indicating that by the time that COPD develops the events that lead to rising tHCy may be independent of the smoking stimulus. Our results support those of a recent study in a Japanese population (Kai 2005) who like us found a mean plasma homocysteine of approximately $12 \mu \mathrm{mol} / \mathrm{L}$ in the COPD patients and showed that a high tHCY predicted more rapid $\mathrm{FEV}_{1}$ decline. However, we have also found that tHCY is related to COPD severity which they did not (Kai 2005). Unlike the Japanese cohort the FEV , $_{1}$ our patients was negatively correlated with tHCY levels and this is consistent with the relationship we found between high tHCY and poor quality of life scores. Kai and colleagues (2005) found that there was a tendency toward a relationship between low arterial oxygen tension and low tHCY in their COPD patients and speculated that this may cause inhibition of enzymes involved in tHCY metabolism in the later stages of COPD, however this relationship was 


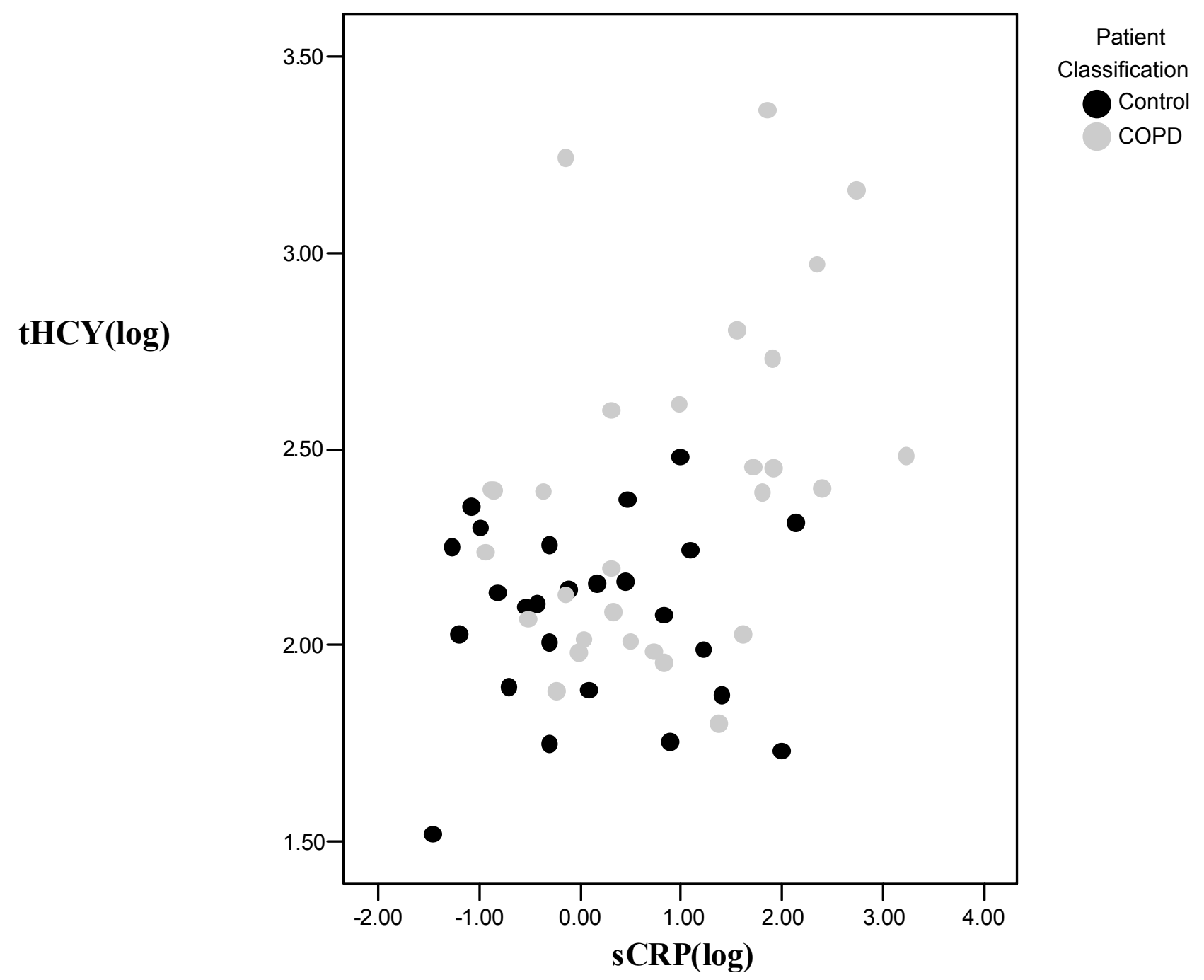

Figure I Relationship between total plasma homocysteine (tHCY) and serum C-reactive protein (sCRP) in 29 COPD patients and 25 asymptomatic controls, rho $=0.377$, $\mathrm{P}=0.005$. Grey circles are asymptomatic controls and black circles are COPD.

not tested in a multivariate analysis. We note however that the mean $\mathrm{FEV}_{1}$ of our patients was greater than that in the Japanese study and so on average our patients were less severe. Several enzymes are involved either directly or indirectly in homocysteine metabolism and mutations in any of the following cystathionine beta-synthase (Mudd 2001), methylenetetrahydrofolate reductase (MTHFR) or methionine synthase reductase (Goyette 1995; Kluijitmans 2003) may contribute to hyperhomocysteinaemia in different populations.

The high levels of HHCY in COPD compared with the controls may well be a marker of unhealthy lifestyles (Rimm 1998; Cleophas 2000). However the finding that tHCY was higher in patients with GOLD stages III/IV disease compared with Stages I/II suggests a role in COPD pathogenesis. This is supported by the finding of an inverse relationship between tHCY and $\mathrm{FEV}_{1} \%$ as well as with poor quality of life scores.
The raised tHCY in COPD has been related to oxidative stress as demonstrated by Andersson et al who showed that tHCY was elevated, but reduced glutathione depressed, in COPD relative to controls (Anderson 2001). Thus, the role of tHCY in COPD may be mediated through its inverse relationship with reduced glutathione. Recent workers have found a relationship between markers of oxidative stress such as reduced glutathione and COPD severity and this is consistent with our hypothesis of a role for $\mathrm{tHCY}$ in the pathogenesis of COPD (Kluchova 2006; Vibhuti 2007).

We found that $\mathrm{HCY}$ levels were positively and independently related to SCRP, a marker of systemic inflammation, mortality and hospitalization in COPD (Dahl 2007), cardiac disease (Zakai 2007) and cardiac disease in COPD (Sin 2003). In our study, median sCRP in normal subjects was similar to that of previously published American and Dutch controls (Sin 2003; Broekhuisen 2005). The difference 


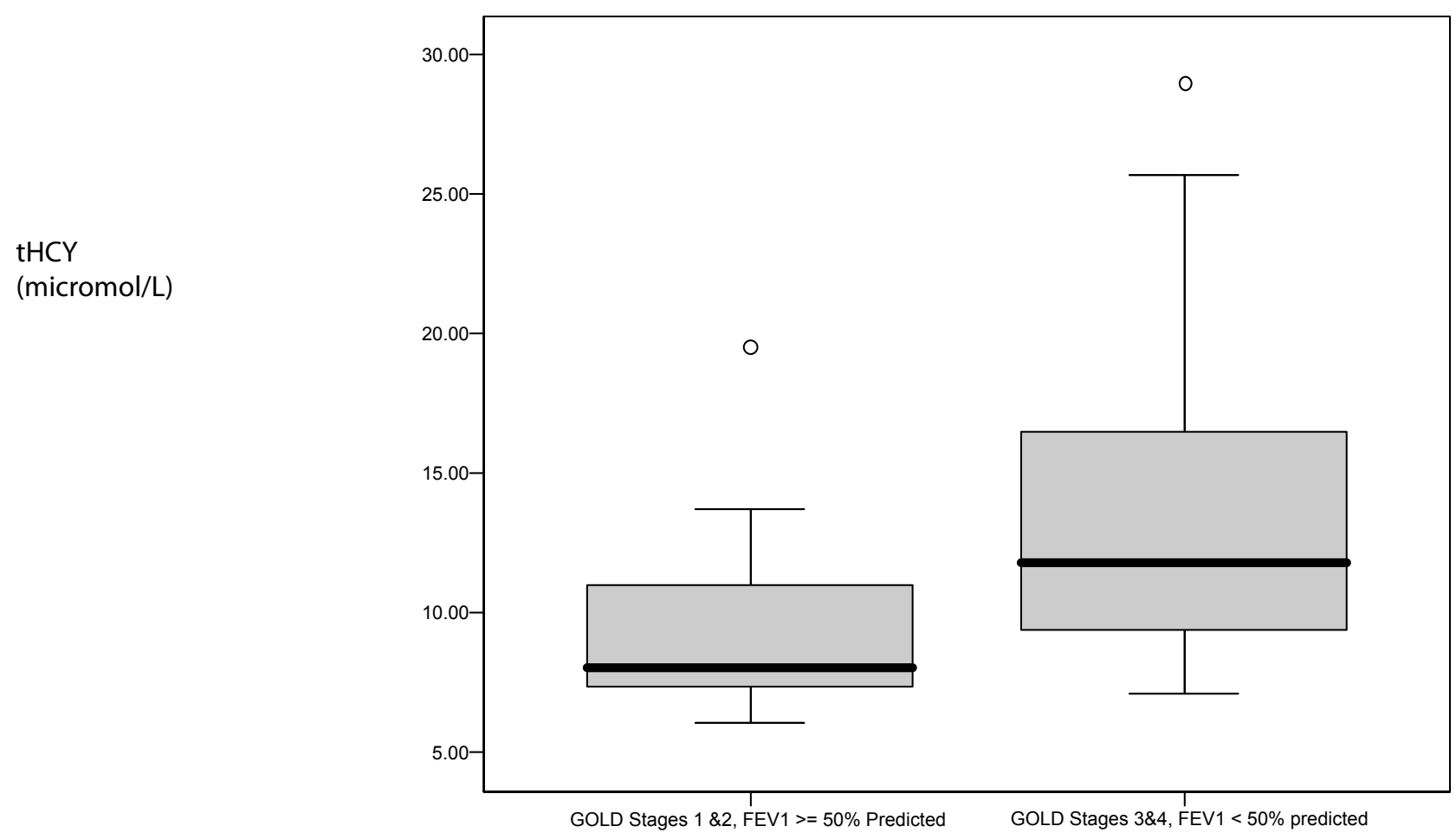

Figure 2 The box plot shows the relationship between total plasma homocysteine (tHCY) and COPD severity in 29 COPD patients, $p=0.023$. Open circles indicate outliers.

in mean sCRP between controls and COPD patients was $2.52 \mathrm{mg} / \mathrm{L}$ in our study which is of the same order of magnitude as the $1.86 \mathrm{mg} / \mathrm{L}$ due to COPD as estimated in a meta-analysis by Gan and colleagues (2004). In our study we have found that circulating levels of sCRP were higher in participants with airflow obstruction than in those without and that SCRP was related to severity of obstruction as Sin and colleagues (2003) found. However, though median SCRP was higher in our more severe COPD patients the sample size was not sufficient to detect a statistically significant difference. Like tHCY, sCRP is also associated with cardiac disease (Zakai 2007). Pulmonary inflammation is a likely cause of systemic inflammation seen in COPD, as supported by a recent study showing that use of inhaled corticosteroids in COPD patients is associated with reduced sCRP and other markers of systemic inflammation (Sin

Table 4 Backward stepwise multiple regression analysis with plasma homocysteine (log) as outcome variable in 54 subjects (29 COPD and 25 healthy controls)

\begin{tabular}{llr}
\hline Dependent variables & Regression coefficient (B) & \multicolumn{1}{c}{$\mathbf{p}$} \\
\hline sCRP (log) & 0.087 & 0.024 \\
COPD & 0.194 & 0.031 \\
Male gender & 0.345 & $<0.001$ \\
Constant & 1.848 & $<0.001$ \\
\hline
\end{tabular}

2004). Finally the positive correlation between sCRP and tHCY reported in our study has also been found in other chronic diseases (Sattar 2007; Schroecksnadel 2007) and this again supports the hypothesis of a possible role for homocysteine in cardiac complications in chronic disease patients. The cause of this association is not clear. Interventional studies have so far shown that increased intake of folate or B12 while reducing tHCY are not associated with however decreased serum inflammatory markers or cardiac events but raised serum folate may have direct effects at multiple sites including atherosclerotic plaques and thus other methods of reducing tHCY may yield different results on serum inflammatory markers (Durga 2005; Bonaa 2006).

In this study of West Indian patients with COPD we have found that two markers, tHCY and sCRP, that have been associated with cardiovascular risk are also associated with COPD and with COPD severity and with each other. In general, for a $10 \%$ decrease in $\mathrm{FEV}_{1}$, all-cause mortality increases by $14 \%$, cardiovascular mortality increases by $28 \%$, and nonfatal coronary events increase by almost $20 \%$ (Anthonisen 2002), similarly, studies of sCRP have shown that sCRP greater than $3 \mathrm{mg} / 1$ is associated with high mortality rates at 10 years (Dahl 2007). Further studies are required to determine the cause of the elevated plasma homocysteine 
levels in COPD patients in this West Indian population and whether tHCY is related to mortality in COPD.

\section{Acknowledgments}

We would like to acknowledge helpful advice from Dr. F. Ramlakhansingh, Prof. D. Ramdath, Prof. M. Omer, Dr. S Pooran, Mr. Desmond Parker, the staff at The Port of Spain General Hospital (POSGH), Biochemistry laboratory at POSGH, and Immunology and Pathology laboratories at Eric Williams Medical Sciences Complex (EWMSC), Faculty of Medical Sciences, University of the West Indies. We are especially grateful to the patients and volunteers who took the time to participate in our study. Funding was departmental. Portions of this manuscript have been presented in abstract form at the 2006 American Thoracic Society Meeting, May 2006 in San Diego, USA.

\section{Conflict of interest}

Dr. Seemungal has received speaking honoraria from GlaxoSmithKline, ASTRA Zeneca, Pfizer, and Boehringer Ingelheim. Dr. Wedzicha has received research grant funding and/or honoraria for lectures and advisory boards from GlaxoSmithKline, Astra Zeneca, and Boehringer Ingelheim. The other authors admit to no conflicts of interest.

\section{References}

[AARC] American Association for Respiratory Care. 1996. AARC Clinical Practice Guideline Spirometry 1996 Update. Reprinted from Respir Care, 41(7):629-36.

[ATS] American Thoracic Society. 1995. Statement on Standardisation of Spirometry 1994 Update. Am J Respir Crit Care Med, 152:1107-36.

Andersson A, Ankerst J, Lindgren A, et al. 2001. Hyperhomocysteinemia and changed plasma thiol redox status in chronic obstructive pulmonary disease. Clin Chem Lab Med, 39:229-33.

Anthonisen NR, Connett JE, Enright PL, et al. 2002. Hospitalisation and mortality in the Lung Health Study. Am J Respir Crit Care Med, 166:333-89.

Barnes PJ. 2000. Medical progress: chronic obstructive pulmonary disease. N Engl J Med, 343:269-80.

Bodi V, Sanchis J, Llacer A, et al. 2005. Risk Stratification in non-ST elevation acute coronary syndromes; Predictive power of troponin I, C-reactive protein, fibrinogen and total plasma homocysteine. Int $J$ Cardio, 98(2):277-83.

Bonaa KH, Njolstad I, Ueland PM, et al. 2006. Homocysteine lowering and cardiovascular events after acute myocardial infarction. $N$ Engl J Med, 354(15):1578-88.

Broekhuizen R, Wouters EFM, Creutzberg EC, et al. 2005. Elevated CRP levels mark metabolic and functional impairment in advanced COPD. Thorax, doi:10.1136/thx.2005.041996.

Buist S ed. 2006. Global Standards for the Diagnosis, Management and Prevention of COPD. MCR Vision Inc.

Cheung F, Cheung SM. 2003. Measuring Personality and values across cultures: imported versus indigenous measures. Online Readings in Psychology and Culture, 6(5).
Cleophas TJ, Hornstra N, van Hoogstraten B, et al. 2000. Homocysteine, a risk factor for coronary artery disease or not? A meta-analysis. Am J Cardiol, 86(9):1005-9, A8.

Cockburn BN, Bermano G, Boodram LL, et al. 2005. Gene symbol: IPF1. Disease: MODY 4. Hum Genet, 116(6):538.

Crapo Ro, Morris AH, Gardnar RM. 1981. Reference spirometric values using techniques and equipment that meets ATS recommendations. Am Rev Respir Dis, 123:654-59.

Dahl M, Vestbo J, Lange P, et al. 2007. Dahl C-reactive Protein is a Strong Predictor of Prognosis in COPD. Am J Respir Crit Care Med, 175(3):250-5.

Danesh J, Collins R, Appleby P, et al. 1998. Direct proinflammatory effects of fibrinogen, C-rective protein, albumin or leukocyte count with coronary heart disease: meta-analyses of prospective studies. JAMA, 279:2165-68.

Davison C. 2004. Translation of fixed-response questionnaires for health research with aboriginal people: a discussion of methods. Pimatsiwin: A Journal of Aboriginal and Indigenous Community Health, 2(2):97-114.

Durga J, van Tits LJH, Schouten EG, et al. 2005. Effect of lowering of homocysteine levels on inflammatory markers: a randomized controlled trial. Arch Intern Med, 165:1388-94.

Fabiosa J, Mohanty S, Smith D, et al. 1997. Conceptual Framework and Software Documentation. Jamaica Technical Manual. CARD Technical Report, 97-TR 33.

Gan WQ, Man SFP, Senthilselvan A, et al. 2004. Association between chronic obstructive pulmonary disease and systemic inflammation: a systematic review and a meta-analysis. Thorax, 59:574-80.

Goyette P, Frosst P, Rosenblatt DS, et al. 1995. Seven novel mutations in the methylenetetrahydrofolate reductase gene and genotype/phenotype correlations in severe methylenetetrahydrofolate reductase deficiency. Am J Hum Genet, 56(5):1052-9.

Harrinarine R, Abiraj V, Ali A, et al. 2005. Prevalence of COPD in acute medical patients in Trinidad. West Ind Med J, 54(Suppl 2):46.

Homocysteine Studies Collaboration. 2002. Homocysteine and Risk of Ischaemic Heart Disease and Stroke: A Meta-analysis. JAMA, 288:2015-22.

Jones PW, Quirk FH, Baveystock CM. 1991. The St. George's Respiratory Questionnaire. Respir Med, 5 Suppl(B):25-31.

Kai S, Nomura A, Morishima Y, et al. 2005. The effect of smoking related hyperhomocysteinaemia on spirometric declines in chronic obstructive pulmonary disease in elderly Japanese. Arch Gerontol Geriatr, 42:117-24.

Kluchova Z, Petrasova D, Joppa P, et al. 2006. The association between oxidative stress and obstructive lung impairment in patients with COPD. Physiol Res, 56(1):51-6.

Kluijtmans LA, Young IS, Boreham CA, et al. 2003. Genetic and nutritional factors contributing to hyperhomocysteinemia in young adults. Blood, 101(7):2483-8.

Miller GJ, Beckles GL, Maude GH, et al. 1989. Ethnicity and other characteristics predictive of coronary heart disease in a developing community: principal results of the St James Survey, Trinidad. Int J Epidemiol, 18(4):808-17.

Mudd HL, Levy, Kraus JP. 2001. Disorders of transsulfuration. In: Scriver CR, Beaudet AL, Sly WS, et al eds. The metabolic and molecular bases of inherited disease, McGraw Hill, New York, pp 2007-56.

National Agriculture Library. 2004. National Nutrient Database for Standard Reference [online]. Accessed 15 January 2004. URL: http://www.nal. usda.gov

Pinto-Pereira L, Clement Y, Da Silva CK, et al. 2002. Understanding and use of inhaler medication by asthmatics in specialty care in Trinidad. Chest, 121:1833-40.

Refsum H, Smith AD, Ueland N, et al. 2004. Facts and recommendations about total plasma homocysteine determinants: An expert opinion. Clin Chem, 50:3-32. 
Rimm EB, Willett WC, Hu FB, et al. 1998. Folate and vitamin B6 from diet and supplements in relation to risk of coronary heart disease among women. JAMA, 279(5):359-64.

Sattar N, Crompton P, Cherry L, et al. 2007. Effects of tumor necrosis factor blockade on cardiovascular risk factors in psoriatic arthritis: a doubleblind, placebo-controlled study. Arthritis Rheum, 56(3):831-9.

Schroecksnadel K, Frick B, Fiegl M, et al. 2007. Hyperhomocysteinaemia and immune activation in patients with cancer. Clin Chem Lab Med, 45(1):47-53.

Scott PW, Mullings RL. 1998. Bronchial asthma deaths in Jamaica. West Indian Med J, 47:129-132.

Seemungal TAR, Donaldson GC, Bhowmik A, et al. 2000. Time course and recovery of exacerbations in patients with chronic obstructive pulmonary disease. Am J Respir Crit Care Med, 161:1608-18.

Seemungal TAR, Donaldson GC, Paul EA, et al. 1998. Effect of exacerbation on quality of life in patients with chronic obstructive pulmonary disease. Am J Respir Crit Care Med, 157:1418-22.
Sin DD, Lacy P, York E, et al. 2004. Effects of fluticasone on systemic markers of inflammation in chronic obstructive pulmonary disease. Am J Respir Crit Care Med, 170:760-5.

Sin DD, Man SFP. 2003. Why are patients with chronic obstructive pulmonary disease at increased risk of cardiovascular diseases? The potential role of systemic inflammation in chronic obstructive pulmonary disease. Circulation, 107:1514-19.

Vibhuti A, Arif E, Deepak D, et al. 2007. Correlation of oxidative status with BMI and lung function in COPD. Clin Biochem, Jun 2; [Epub ahead of print].

Wedzicha J, Seemungal T, MacCallum P, et al. 2000. Acute exacerbations of chronic obstructive pulmonary disease are accompanied by elevations of plasma fibrinogen and serum IL-6 levels. Thromb Haemost, $84: 210-5$.

Zakai NA, Katz R, Jenny NS, et al. 2007. Inflammation and hemostasis biomarkers and cardiovascular risk in the elderly: the cardiovascular health study. J Thromb Haemost, Mar 21; [Epub ahead of print]. 
